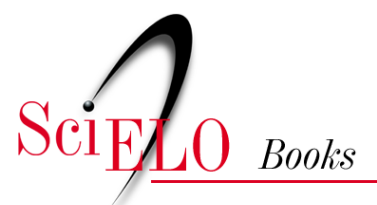

\title{
Capítulo 6 - Atenção Diferenciada e Medicalização da Gestação, do Parto e do Pós-Parto
}

\author{
Raquel Paiva Dias-Scopel
}

\section{SciELO Books / SciELO Livros / SciELO Libros}

DIAS-SCOPEL, R.P. Atenção Diferenciada e Medicalização da Gestação, do Parto e do Pós-Parto. In: $A$ Cosmopolítica da gestação, do parto e do pós-parto: autoatenção e medicalização entre os índios Munduruku [online]. 2nd ed. rev. Rio de Janeiro: Editora FIOCRUZ, 2018, pp. 155-165. Saúde dos Povos Indígenas collection. ISBN: 978-65-5708-014-6. https://doi.org/10.7476/9786557080146.0010. International license.

Todo o conteúdo deste trabalho, exceto quando houver ressalva, é publicado sob a licença Creative Commons Atribição 4.0. 


\section{Atenção Diferenciada e Medicalização da Gestação, do Parto e do Pós-Parto}

Neste capítulo apresento dados sobre o parto na cidade, compreendendo-os em um contexto mais amplo de pluralidade de formas de atenção à saúde. Destaco que as práticas de autoatenção relativas ao parto realizadas pelas famílias Munduruku da Terra Indígena Kwatá-Laranjal (TIKL) permitem compreender o parto na cidade como parte das estratégias de articulação transacionais entre as diversas formas de atenção disponíveis para o grupo. Minha intenção não é apenas ressaltar os antagonismos entre as diferentes formas indígenas e biomédicas de atenção ao parto, mas destacar que se por um lado os indígenas têm feito as articulações entre diferentes formas de atenção à saúde-doença-enfermidade, por outro cabe confrontar o processo amplo de medicalização da saúde indígena que, paradoxalmente, não é acompanhado de aumento da eficiência dos serviços de saúde prestados.

A diretriz da Política Nacional de Atenção à Saúde dos Povos Indígenas (Pnaspi), de 2002, que propõe uma "atenção diferenciada" capaz de respeitar e valorizar os saberes indígenas no trato com a saúde e com a proposta de articulá-los aos serviços biomédicos, envolve alguns desafios que precisam ser mais bem delimitados. Principalmente quando, no cenário internacional, estudiosos dos sistemas de parto em diferentes culturas e contextos diversificados de disponibilidade de tecnologias biomédicas assinalam a expansão mundial da medicalização do parto, já desde o final da década de 1970 (Sargent G Bascope, 1996). Assim, se por um lado a Pnaspi propõe uma articulação entre as práticas indígenas de atenção à saúde e as práticas biomédicas, por outro convive com a marcada expansão do modelo biomédico, pautado por noções particulares sobre doença, tratamento e eficácia. Ao mesmo tempo que a Pnaspi indica uma atenção diferenciada, há também a tendência dos serviços oficiais de saúde a ignorar e até negar os saberes e práticas de autoatenção utilizados pela população. Isso nos leva a questionar o modo como a expansão e a cobertura da atenção primária, isto é, aquela que é ofertada no interior das terras indígenas, vêm sendo realizadas. Embora a Pnaspi indique a capacitação e a formação de recursos humanos para atuar em contextos interculturais como estratégias para a promoção da atenção diferenciada, a autoridade biomédica tem não só dominado as práticas de atenção ao parto em âmbito 
mundial, como também definido os processos de validação dos conhecimentos e das práticas indígenas. ${ }^{70}$

Ao analisar dificuldades encontradas para uma articulação entre os modelos de atenção à saúde-doença indígenas e biomédicos, Langdon (2013: 27) observa que "a distribuição de conhecimentos e os atributos das categorias de especialistas tradicionais não têm correspondência com os da biomedicina". Em consequência, os equívocos da busca por uma equivalência de domínios e de atuação podem gerar também a emergência de especialistas, sem que isso implique reconhecimento e legitimidade perante os demais membros indígenas. No contexto munduruku, conforme sugiro, a distribuição de saberes e práticas não está limitada aos especialistas, mesmo entre aqueles socialmente legitimados (Scopel, 2013).

Alguns exemplos permitem concluir que princípios de ordem social e cultural particulares a cada grupo contribuem, de forma direta, na distribuição dos saberes e nas decisões sobre que especialista consultar durante o parto, e quando consultá-lo. O estudo de Sargent e Bascope (1996) sobre sistemas de parto, por exemplo, em uma comunidade maia, mexicana, os Yaxuna, apresenta a personalidade, a história de vida, as relações de parentesco e o status da família diante dos demais membros da comunidade como os princípios que constituem a legitimidade das especialistas em parto. Outro exemplo é o trabalho de Platt (2002) entre os Macha, um grupo de falantes quéchua, na Bolívia, onde o parto é primeiramente um evento doméstico, de foro íntimo. Lá, a parturiente é auxiliada por seu marido e filhos mais velhos. No primeiro parto, as mulheres podem contar com a ajuda de suas sogras ou outras mulheres mais velhas da vizinhança com experiência de partejar. As "parteiras especializadas" são chamadas apenas em casos de complicações no parto.

No caso das práticas de autoatenção ao parto realizadas pelos Munduruku, observa-se que entre eles também os saberes sobre parto estão horizontalmente distribuídos entre os membros da comunidade, especialmente entre as mulheres mais velhas, embora alguns especialistas como pajés, homens ou mulheres, e "parteiras", possam igualmente ser chamados a atuar na hora do parto. Ademais, os relatos de parto das mulheres Munduruku indicam que os saberes e práticas sobre partos, além de não serem limitados aos especialistas socialmente legitimados, também sinalizam a dificuldade em encontrar uma correspondência com categorias profissionais da biomedicina - por exemplo, a obstetrícia. Além das questões de ordem sociocultural, devemos nos perguntar também sobre qual o impacto do acesso aos recursos biomédicos e das interações sociais com os profissionais da saúde, especialmente com aqueles que atuam na atenção primária, na tomada de decisão sobre quem consultar durante a gestação e sobre onde realizar o parto.

Segundo Langdon (2013), os sistemas de parto indígenas aparecem como um desafio para as políticas públicas de saúde indígena no Brasil relacionado aos 
princípios de articulação com as medicinas indígenas. Em primeiro lugar, porque raramente as práticas de cuidados se encontram limitadas a especialistas, e em segundo porque promovem um conjunto de práticas que dificilmente a biomedicina poderia instrumentalizar. Os exemplos das práticas de autoatenção relativas à gestação, ao parto e ao pós-parto entre os Munduruku da TIKL incluem práticas e valores relacionados com a cosmografia do grupo, promovem relações afetivas significativas na manutenção das relações sociais familiares e repercutem sobre a saúde e a socialidade da família elementar e extensa, além de articular as relações de aliança política.

Portanto, as práticas de autoatenção relativas ao nascimento entre os Munduruku evidenciam uma compreensão ampla acerca da concepção, da gestação, do parto e do pós-parto na qual intervêm elementos socioculturais e cosmográficos pertinentes à reprodução biossocial do grupo, seja a família elementar ou, por consequência, a própria sociedade munduruku. Além disso, os saberes compartilhados sobre o processo de nascimento, como vimos, diferem das concepções anatômicas e fisiológicas praticadas pelo modelo biomédico, restrito a uma abordagem biológica do corpo humano. Isso tem repercussões nos processos de legitimação de determinados saberes como, por exemplo, no reconhecimento das práticas de autoatenção instauradas pelo desejo ou pelo "abalo de criança" na gestação, de aguentar a dor em silêncio no trabalho de parto, de "puxar a mãe do corpo" ou da reclusão no pós-parto, que, embora para os Munduruku sejam fundamentais para a sua saúde e bem-estar, não são aprovadas como um benefício pela biomedicina. Ainda que esta não tenha encontrado uma razão em alguns saberes das medicinas indígenas, "isto não diminui a importância [dessas práticas] para o sistema de parto como um sistema de cuidados à saúde" (Langdon, 2013: 31-32).

É no reconhecimento dessas diferenças entre o modelo indígena e o modelo biomédico no trato com a saúde que, em certo sentido, a Pnaspi se pauta para propor uma atenção diferenciada. Todavia, os profissionais da saúde que atuam nos subsistemas de saúde indígena desconhecem como promover uma atenção diferenciada, bem como as estratégias para incrementar uma articulação entre os saberes indígenas e biomédicos relativos aos processos de saúde/doença/atenção (Diehl, Dias-Scopel G Langdon, 2012; Langdon, 2013).

Além disso, quando determinadas práticas são selecionadas com o objetivo de instrumentalizá-las para incorporá-las em programas de saúde, corre-se o risco de descontextualizá-las, deixando de considerar seu entorno social e cultural. Esse pode ser o resultado das tentativas de integração dos especialistas indígenas nos programas de saúde sobre o parto. Talvez um efeito das tentativas de integrar indígenas ao modelo biomédico tenha sido o caso das "parteiras" Munduruku, em que a iniciativa de um curso para parteiras, ao buscar identificar especialistas, fomentou a emergência de um papel social, a "parteira" que atua entre diferentes 
famílias extensas. Então, a questão que se coloca é: quais são as refrações dessas iniciativas nas relações sociais do grupo e também nas relações sociais com os demais membros da equipe de saúde dos serviços biomédicos?

Ao diferenciar as noções de articulação e de integração, Langdon (2013: 32) identifica outro problema como consequência de estratégias equivocadas:

Oposta ao princípio da articulação, a noção de integração implica em instrumentalização das práticas da medicina tradicional percebidas como eficazes pela ciência ocidental. A noção de integração de práticas tradicionais nas ações de saúde realizadas pelas equipes médicas tira a especificidade do outro. A estratégia de integração das práticas tradicionais remete ao problema da hegemonia e dominação da biomedicina em decidir quais práticas são legítimas, quais devem ser cultivadas e quais devem ser eliminadas.

É necessário reconhecer os processos de indigenização, conforme sintetizou Sahlins (2007), para indicar a agência das populações indígenas nos processos de expansão das fronteiras capitalistas, de modo a prover o próprio desenvolvimento. É preciso considerar também que os contextos de pluralidade médica implicam juízos de valor sobre as diferentes formas de atenção à saúde, doença e tratamento (Menéndez, 2005; Sargent G Bascope, 1996). Conforme assinala Ortner (2006), se por um lado os atores sociais, individuais ou coletivos, têm agência capaz de reproduzir e transformar relações estruturais e sistematizadas ou a elas resistir, por outro essas mesmas relações sistemáticas coagem os sujeitos e constituem os instrumentos e elementos que moldam suas subjetividades. Portanto, no processo de expansão biomédica é preciso ter em conta os paradoxos advindos dos confrontos entre diversos regimes de poder e intencionalidades. Isso significa observar em que nível da rede de saúde na qual o Subsistema de Atenção à Saúde Indígena (Sasisus) está inserido há uma promoção e valorização de algumas formas de atenção à saúde e às enfermidades em detrimento e com desvalorização de outras. Afinal, o Sasisus integra diferentes níveis de atenção: a atenção primária, ofertada no interior das aldeias indígenas, e as atenções de média e alta complexidade, ofertadas nas redes do Sistema Único de Saúde (SUS).

\section{O parto na cidade}

Desde a ampliação da cobertura e do acesso aos serviços de saúde biomédicos, o parto hospitalar também se tornou um recurso opcional utilizado pelas mulheres indígenas. E as mulheres Munduruku o têm utilizado, realizando partos no hospital público de Nova Olinda do Norte, Amazonas, cidade vizinha à TIKL. Sugiro que a expansão crescente da medicalização do parto e o acesso aos serviços de atenção pré-natal são parte dos fatores macrossociais que interveem na escolha 
do local de parto. Nesta seção, apresentarei dados de observação participante para circunscrever o ponto de vista das mulheres Munduruku sobre a escolha do local de parto. As rodas de conversa ao entardecer foram os locais e momentos privilegiados para minha aproximação dos fatores microssociais envolvidos no processo de decisão sobre onde parir. As conversas com os profissionais da Equipe Multidisciplinar de Saúde Indígena (EMSI) que atuavam nos polos da TIKL, na época da pesquisa de campo, foram importantes também para que eu compreendesse as razões que cooperavam no processo de tomada de decisões das gestantes Munduruku. Escrevo sobre isso para que o leitor compreenda os sentidos atribuídos ao parto hospitalar, os quais resultam de uma série de relações sociais entre as gestantes, seus maridos, familiares e também os especialistas indígenas como "parteiras", pajés e profissionais da EMSI.

Embora os dados epidemiológicos que obtive durante o trabalho de campo - acerca das ações dos serviços de atenção biomédica à gestação, parto e pós-parto ofertados aos indígenas da TIKL - não permitam avaliar uma tendência nos indicadores de saúde, ao menos servem para indicar que as mulheres Munduruku têm realizado partos na aldeia e partos no hospital e, em alguns casos, cesáreas.

Tabela 1 - Partos na aldeia e na cidade. Polo-Base Kwatá, 2008-2010

\begin{tabular}{c|c|c|c|c|c}
\hline Ano & Total de partos & \multicolumn{2}{|c|}{ Partos na aldeia } & \multicolumn{2}{c}{ Partos no hospital } \\
\hline 2008 & 28 & 22 & $79 \%$ & 6 & $21 \%$ \\
\hline 2009 & 49 & 22 & $45 \%$ & 27 & $55 \%$ \\
\hline 2010 & 66 & 33 & $50 \%$ & 33 & $50 \%$ \\
\hline
\end{tabular}

Tabela 2 - Partos cesarianos. Polo-Base Kwatá, 2008-2010

\begin{tabular}{c|c|c|c}
\hline Ano & Total de partos & \multicolumn{2}{|c}{ Número de cesáreas } \\
\hline 2008 & 28 & 2 & $7 \%$ \\
\hline 2009 & 49 & 10 & $20 \%$ \\
\hline 2010 & 66 & 11 & $17 \%$ \\
\hline
\end{tabular}

Fontes: os dados relativos aos partos das mulheres indígenas Munduruku foram obtidos em duas fontes distintas; os dados referentes ao ano de 2008 e 2009 foram coletados em 2010 no Distrito Sanitário Especial Indígena Manaus, e os dados de 2010 foram obtidos em 2011 diretamente com a enfermeira do Polo-Base Kwatá, na aldeia homônima.

Esses dados indicam que em 2008 os partos domiciliares corresponderam a $79 \%$ do total de partos realizados naquele ano nas aldeias adstritas ao Polo-Base Kwatá. Do total de partos, 21\% foram hospitalares. Note-se que 7\% do total foram cesáreas. Em 2009, 45\% foram feitos na aldeia e 55\% no hospital, sendo que as 
cesarianas representaram 20\% do total de partos. Em 2010, 50\% foram hospitalares e, destes, $17 \%$ foram cesáreas. Nesses dados, chama a atenção a alta porcentagem de partos domiciliares, realizados nas aldeias. Todavia, destaca-se também a porcentagem de cesáreas referente aos partos hospitalares, sobretudo se considerarmos os dados relativos ao ano de 2009, quando mais da metade dos partos em hospitais foram cesarianos.

A medicalização do parto já tem longa data no contexto urbano brasileiro, mas ainda é um fato recente para as populações indígenas no Brasil. Entre os Munduruku da aldeia Kwatá, nenhuma mulher acima de 40 anos tinha dúvida quanto ao local do parto, que seria em sua casa, na aldeia, com o auxílio de uma mulher mais velha ou de uma "parteira" ou pajé. Do mesmo modo, os cuidados relativos à gestação eram realizados no interior da família extensa, eventualmente contando com o recurso a um(a) especialista indígena. Atualmente, a medicalização do parto entre as mulheres Munduruku da TIKL inicia-se já na gestação, com o programa de acompanhamento pré-natal, uma medida das políticas públicas de saúde, mas também daquelas voltadas para a diminuição da desigualdade social no Brasil, que incentivam as mulheres a realizarem o controle mensal durante a gestação no sistema de saúde, apesar do acesso restrito à alta tecnologia obstétrica. Entretanto, parece que as ideologias subjacentes ao modelo médico hegemônico antecedem e persistem, independentemente do contexto de baixa ou alta tecnologia obstétrica. Assim, não obstante o acesso ou não aos recursos biomédicos, sobretudo aqueles envolvidos na medicalização do parto, é fato que o discurso e a ideologia biomédicos sobre a necessidade de parto hospitalar e de laqueadura eram temas de conversação e de crítica entre as mulheres Munduruku da TIKL, já à época da pesquisa de campo.

Os dados secundários comprovam que as mulheres Munduruku realizaram partos no hospital. Todavia, os motivos envolvidos no processo de tomada de decisão sobre onde parir ficam mais claros quando analisamos os dados obtidos durante o trabalho de campo. Conforme dito, concentrei minhas atividades de observação participante em um segmento residencial. Das sete mulheres gestantes da família extensa que moravam nesse segmento, três optaram por parir na cidade. Lana optou pelo parto hospitalar porque estava decidida a fazer a laqueadura, procedimento cirúrgico de esterilização feminina. Por conta dessa decisão, Lana fez cesariana.

A laqueadura era tema de conversa entre as mulheres Munduruku, especialmente quando o assunto era a escolha pelo parto hospitalar ou por um método permanente e efetivo contra a concepção. Uma professora Munduruku, ao tentar entender por que eu vinha de uma família tão pequena, com apenas uma irmã e um irmão, apresentou as razões para ter feito laqueadura. Sua última gestação havia sido menos de um ano atrás. Ela vinha de uma família numerosa e contou que seu pai a aconselhou a se casar e "a fazer filhos para não acabar a geração". A professora se referia à continuação da família ao falar da geração. Ela observou 
minha procedência de uma diminuta família e concluiu que "a sociedade envolvente pensa diferente". Exemplificou essa diferença rememorando as recomendações que as mulheres Munduruku escutavam quando faziam o pré-natal: "Dizem que muito filho faz mal para a saúde da mulher, que filho fica criado assim, ao vento".

Cumpre esclarecer que, segundo consta no manual técnico Pré-Natal e Puerpério: atenção qualificada e humanizada, cabe aos profissionais da atenção básica promover "ações educativas" sobre, entre outras, a "importância do planejamento familiar, num contexto de escolha informada, com incentivo à dupla proteção" (Brasil, 2005: 32-34). Ao que parece, na ação educativa para o planejamento familiar realizada durante as consultas pré-natal na TIKL fala-se sobre um número ideal de filhos (Dias-Scopel, Scopel G Langdon, 2017). Todavia, não posso afirmar que as EMSIs tenham incluído a recomendação de fazer laqueadura em suas ações educativas no pré-natal. Entretanto, a avaliação de que atualmente há uma tendência à procura pela laqueadura foi comum entre muitas mulheres Munduruku. Isso mesmo em um contexto em que as mulheres compartilhavam diversos saberes sobre práticas anticonceptivas por meio do uso de remédios caseiros e de métodos biomédicos, em especial "injeção para não engravidar" (anticoncepcional injetável), obtidos gratuitamente nos postos de saúde de Nova Olinda do Norte. De qualquer forma, qualquer que tenha sido a recomendação feita pelos profissionais da EMSI durante o acompanhamento pré-natal relativo ao planejamento familiar, a laqueadura é um procedimento biomédico que vem ganhando espaço entre as práticas anticonceptivas das mulheres Munduruku, segundo uma opinião comum, inclusive dos profissionais da saúde. Além disso, a indicação do parto hospitalar tende a ser reiteradamente afirmada durante as consultas do pré-natal.

Segundo uma das técnicas de enfermagem do Polo-Base Laranjal, "toda primípara mandamos para Nova Olinda do Norte", ou seja, para a rede municipal do SUS para realizar o parto hospitalar. Curiosamente, a idade e a inexperiência em parto também apareceram nas avaliações das mulheres Munduruku com quem conversei nas aldeias Kwatá, Niterói, Caioé e Fronteira, adstritas ao Polo-Base Kwatá, como critérios considerados no processo decisório sobre o local do parto. Foi, por exemplo, o caso de Itapema, uma jovem de 17 ou 18 anos, que teve seu primeiro parto no hospital de Nova Olinda do Norte. Quando visitei Itapema, neta de minha anfitriã Ceci, que estava morando com sua mãe, Rita, enquanto cumpria o resguardo "de parto", foi-me dito que ela havia sido levada para o hospital porque "era muito nova". Foi Rita quem afirmou o motivo da escolha pelo parto hospitalar e foi ela quem acompanhou sua filha durante e após o parto, enquanto permaneceram na Casa de Apoio à Saúde do Índio (Casai). A permanência na Casai após o parto, por um período que variou entre sete e 15 dias, foi seguido pelas mulheres Munduruku como parte das práticas de autoatenção ao pós-parto. Outras mulheres realizaram o parto hospitalar pelo mesmo motivo que levou Itapema à escolha 
desse local para parir durante o período da pesquisa de campo. Gigi, outra jovem de 16 anos de idade, também fez o primeiro parto no hospital. A mãe de Gigi era agente indígena de saúde (AIS) e a acompanhou durante e após o parto, quando permaneceram na Casai. Novamente, a mãe de Gigi justificou a escolha com a idade da filha, "muito nova". Gigi estava morando com os pais porque ficara viúva pouco antes do nascimento do filho.

Quando fiz observação participante na Casai, a maioria das pacientes em trânsito, isto é, que estavam pernoitando ali, era gestante ou estava no pós-parto. Naquele espaço, outro fator foi elencado como critério para a eleição do parto hospitalar pelas mulheres e seus acompanhantes - na maioria dos casos, as mães das gestantes ou seus maridos. A busca por segurança diante da virtualidade de um parto complicado motivou tanto gestantes primíparas quanto experientes a buscar o parto hospitalar. A principal razão por elas enunciada foi evitar a morte da mãe ou do bebê por causa de possíveis complicações na hora do parto. Assim, o parto hospitalar apareceu como alternativa relacionada à expectativa de um parto seguro. A possibilidade de um parto complicado, especialmente na época da seca, quando aumentam as dificuldades de deslocamento das aldeias até o polo-base, onde a EMSI atuava, ou até a cidade de Nova Olinda do Norte para ser assistida no hospital, motivou muitas famílias de diferentes aldeias a procurarem o parto hospitalar com antecedência, fosse primeiro parto ou não. Foi o caso, por exemplo, de Vani e de Laura. Vani e seu esposo, à época da pesquisa de campo um AIS e conselheiro distrital de saúde, optaram pelo parto hospitalar porque o deslocamento seria mais difícil e demorado, por conta das distâncias que aumentavam na época da seca, caso houvesse alguma complicação. Eles moravam em uma pequena aldeia adstrita ao Polo-Base Laranjal, no rio Mari-Mari, não muito distante da aldeia onde o polo-base ficava sediado. Vani foi acompanhada de seu marido e os dois ficaram na Casai por 15 dias após o parto. Ela tinha mais de 30 anos e era mãe de cinco crianças, das quais apenas as duas últimas nasceram no hospital. As outras três meninas haviam nascido na aldeia com a ajuda da "parteira" da aldeia Mucajá, próxima daquela em que moravam. Laura, por sua vez, morava em uma distante aldeia no rio Canumã, a horas de viagem da aldeia onde a EMSI do polo-base ficava sediada. Ela e seu esposo, também um AIS, optaram pelo parto hospitalar da última filha, com 5 meses na época da pesquisa de campo, por receio de um parto complicado e por conta da distância dessa aldeia, inclusive, das demais aldeias naquele rio. Além disso, os pais dela já eram falecidos e os pais dele moravam em Nova Olinda do Norte. Laura também tinha mais de 30 anos e era mãe de sete crianças.

É compreensível o receio dos Munduruku e a preocupação em deslocar uma mulher em trabalho de parto, a qualquer hora do dia ou da noite, como motivação para optar antecipadamente pelo parto hospitalar, na medida em que, em suas ações, 
alguns profissionais da EMSI manifestaram uma rejeição às práticas das "parteiras". Conforme expressou uma técnica de enfermagem do Polo-Base Laranjal, "diz que as parteiras mandam fazer força antes da hora, já a equipe [EMSI] avalia pela dilatação". Por esse motivo, quando a EMSI chegou para fazer o parto "a mulher já estava toda atirada, cansada". Embora ela estivesse falando especificamente de um parto realizado no interior da TIKL, no qual havia participado ativamente, tendo mesmo chegado a realizar uma episiotomia, sugiro que o testemunho dessa técnica de enfermagem possa estar evidenciando um discurso biologicista e medicalizado sobre o parto. Ainda mais, sugiro que esse tipo de discurso torna visível a maneira como profissionais da saúde reforçam uma relação de subordinação da mulher e dos saberes indígenas ao saber biomédico.

Como vimos, esses discursos contradizem a narrativa de Araci, por exemplo, sobre a hora correta de fazer força. Essas contradições emergem em um contexto no qual muitos partos foram realizados com sucesso em casa, com o auxílio das mulheres mais velhas da família extensa ou com a participação dos especialistas indígenas e, ainda, eventualmente, dos profissionais da saúde. Em certo sentido, a necessidade de parto hospitalar, incentivada pelos profissionais da EMSI - seja de forma direta, com o encaminhamento das primíparas à rede do SUS, seja de forma indireta, com a desqualificação das práticas munduruku relativas ao parto -, contribuiu para a construção do parto como um evento cercado de riscos e, principalmente, para sua medicalização.

Todavia, a ideia de risco de vida, como situação de vulnerabilidade que pode levar à morte da parturiente e do bebê, não é totalmente estranha aos Munduruku. A procura por partos hospitalares foi também uma demanda de algumas mulheres indígenas cuja motivação teve origem nas avaliações que emergiram da prática de "pegar barriga". Iara estava planejando parir no hospital de Nova Olinda do Norte porque tanto o pajé quanto sua cunhada afirmaram que seu bebê estava "sentado" quando "pegaram a barriga" dela ao longo da gestação. Conforme vimos, Iara fora "pegar barriga" durante todo o período da última etapa da pesquisa de campo para "ajeitar o bebê no nascedouro", ou seja, para endireitar a posição fetal, e decidira parir no hospital da cidade de Nova Olinda do Norte incentivada pelo pajé que a acompanhou durante a gestação. Essa decisão estava embasada no diálogo com um especialista Munduruku e na avaliação da posição fetal, cuja inadequação resultaria em um parto difícil e representava riscos de vida para a mãe e, especialmente, para o bebê, segundo a memória social compartilhada entre os Munduruku acerca de partos seguidos de morte por causa da posição do bebê na hora do nascimento. As mulheres mais velhas contavam casos de óbito neonatal de bebês que nasceram "sentados" ou "de pé" e casos de partos bem-sucedidos, apesar da posição inadequada do bebê na hora do nascimento, principalmente por conta da atuação de pajés e "parteiras". 
Em contrapartida, nesse cenário é importante ainda considerar os riscos das cesáreas desnecessárias para a saúde materno-infantil. Desde 1998 o Ministério da Saúde tem incentivado a diminuição do número de cesáreas, por reconhecer que esse procedimento tem contribuído para os índices de morbimortalidade neonatal:

\begin{abstract}
Embora essa realidade tenha melhorado progressivamente nos últimos anos, a assistência materno-infantil é ainda um significativo problema de Saúde Pública no País. Em algumas regiões, registram-se, ainda, alarmantes índices de morbimortalidade materna e neonatal. Isso decorre por diversos fatores, como a precariedade ou inexistência da realização de pré-natal, insuficiência nas condições gerais de infraestrutura e de materiais e equipamentos, capacidade instalada e operacional dos hospitais que realizam partos no País. A alta taxa de cesarianas verificada tem contribuído significativamente para a ampliação dessa morbimortalidade. O parto cirúrgico traz cerca de sete vezes mais risco para a mãe e o bebê. (Brasil, 2002b: 81)
\end{abstract}

No Brasil e mundo afora, há inúmeros fatores que interferem na opção pelo parto hospitalar (Pérez-Gil, 2007a; Sargent G Bascope, 1996). Podemos citar, por exemplo, questões logísticas de deslocamento e proximidade dos centros urbanos; questões de ordem sociocultural e histórica; e a crescente expansão do modelo biomédico e da medicalização do parto. No contexto da TIKL, de alguma forma o sistema de saúde tem incentivado e estimulado as mulheres Munduruku a parir nos hospitais da cidade. E, de alguma forma, ideias de planificação familiar, orientadas por uma visão particular de desenvolvimento socioeconômico, têm incentivado algumas mulheres Munduruku a realizar a laqueadura, o que tem impactado diretamente sobre a realização de cesarianas. A preferência pelo parto cesariano tem sido um ponto crucial na fala dos Munduruku de Canumã, especialmente quando associado à prática da laqueadura. As mulheres Munduruku reconheceram a busca pela laqueadura como resultado do diálogo e do contato com os serviços de saúde ofertados pelo governo brasileiro.

Em síntese, a escolha pelo parto hospitalar foi motivada por diferentes expectativas construídas a partir do diálogo com diversos atores sociais, entre os quais mães, maridos, especialistas indígenas (pajé e "parteiras") e profissionais da saúde. Embora a motivação fosse diferente conforme as relações sociais estabelecidas, a ideia de risco ou de um parto difícil apresenta-se, em determinadas circunstâncias, como um paralelo entre as práticas indígenas e as biomédicas relativas ao nascimento, cujo foco é o bem-estar da mãe e do bebê. Nesse sentido, os profissionais da saúde e as práticas de medicalização do parto encontram um terreno fértil e, portanto, impõem a necessidade de uma atuação crítica a fim de evitar a medicalização excessiva e desnecessária, embasada mais em um procedimento padrão do que em uma avaliação caso a caso. 


\section{Nota}

70 Sargent e Bascope (1996) concluíram que mesmo naqueles contextos em que se verificava acesso restrito à alta tecnologia, isto é, nos hospitais, com profissionais e aparatos biomédicos, era possível identificar a expansão da autoridade biomédica sobre o parto. 